\section{Análisis y propuesta para el fortalecimiento de cadenas productivas en las zonas de influencia directa de Southern Peru}

\author{
Recepción: Agosto de 2006 / Aceptación: Noviembre de 2006
}
(1) Juan Ojeda Sarmiento
(2) Roberto Tello Yuen
(3) Brack Hernández Carranza

\section{RESUMEN \\ El presente estudio es una propuesta técnico económica para el fortalecimiento de las cadenas productivas agrícolas en su eslabón primario, desarrollado en las zonas de influencia directa de Southern Peru. El estudio incluye la caracterización, la identificación y el diagnóstico de las principales cadenas productivas. Este diagnóstico permitió seleccionar a la cadena productiva del orégano como la de mayor impacto económico para los agricultores de la zona, concluyendo el trabajo con propuestas técnicas en el corto y largo plazo, con el objetivo de fortalecer económicamente la posición de los agentes primarios.}

Palabras Clave: Cadenas productivas, fortalecimiento económico, desarrollo agrícola, agentes primarios.

Program of fortification of the PRODUCTIVE CHAINS IN THE ZONES OF direct influence of Southern Peru ABSTRACT

The present study is economic - technical proposal for the fortification of the agricultural productive chains in its primary link, developed in the zones of direct influence of Southern Peru. The study includes the characterization, the identification and the diagnosis of the main productive chains. This diagnosis allowed to select to the productive chain of the oregano like the one of greater economic impact for the agriculturists of the zone, concluding the work with technical proposals in the short and long term, with the objective economically to fortify the position of the primary agents.

Key words: Productive chains, economic fortification, agricultural development, primary agents.
I N T ROD U C C I ÓN

El descuido del agro en las cuatro últimas décadas es, en parte, la causa de una baja productividad en el campo. En la estructura productiva del sector se presenta una serie de elementos adversos como: la producción atomizada, individualizada y sin planeación, que impide su desarrollo competitivo y que ha generado inequidad, deficiencia y la consecuente pobreza, en particular, en las regiones alto andinas de Tacna y Moquegua.

Esta situación parece llamar la atención del Estado que, actualmente, impulsa programas de reducción de la pobreza, promoviendo el desarrollo del sector agrario en las zonas alto andinas; sin embargo, este esfuerzo debe ir acompañado de un diagnóstico previo de las cadenas productivas existentes, que privilegie sólo aquellas que tienen mayor impacto en la población.

Este estudio de las cadenas productivas en las zonas de influencia (las regiones de Moquegua y Tacna) de la empresa minera Southern Peru, es un esfuerzo por construir una estructura productiva equitativa, que fortalezca económicamente la posición de los agentes primarios, que en este caso son los agricultores de las zonas en mención.

CADENAS PRODUCTIVAS
DE SOUTHERN LAS LONAS DE

Las cadenas productivas identificadas en las zonas de estudio se presentan en el cuadro 1.

SELECCIÓN DE LA CADENA PRODUCTIVA A FORTALECER

El criterio para la selección de la cadena productiva a fortalecer, desde el punto de vista del agricultor o eslabón primario, es la utilidad bruta neta (ver cuadro 2) del cultivo por hectárea, su impacto en la generación de empleo local y su perspectiva en el mercado.

Asimismo, en la figura 1 se observa que la cadena productiva del orégano aporta al productor en promedio S/.16 015 por hectárea, esta cifra se

(1) Magíster en Gestión Energética, Universidad de Koblenz (Alemania).

Jefe Administrativo de la Superintendencia de Relaciones Públicas y Comunitarias, Southern Peru E-mail: jojeda@southernperu.com.pe

(2) Ingeniero Industrial. Profesor del Departamento de Ingeniería de Sistemas e Informática, UNMSM. E-mail: rtelloy@unmsm.edu.pe

(3) Egresado de la Facultad de Ingeniería Industrial, UNMSM.

E-mail: brackbrave@hotmail.com 
Cuadro 1. Ubicación de zonas de estudio e identificación de cadenas productivas en el sector agrícola

\begin{tabular}{|c|c|c|c|}
\hline Lugar & Ubicación & Población & $\begin{array}{c}\text { Principales Cadenas } \\
\text { Productivas }\end{array}$ \\
\hline $\begin{array}{c}\text { Provincia de } \\
\text { Candarave }\end{array}$ & Región Tacna & 8543 habitantes & Alfalfa, orégano, maíz, papa. \\
\hline Distrito de llabaya & Región Tacna & 5359 habitantes & $\begin{array}{c}\text { Orégano, cebolla, alfalfa y ají } \\
\text { amarillo. }\end{array}$ \\
\hline Distrito de Torata & Región Moquegua & 5288 habitantes & $\begin{array}{c}\text { Alfalfa, orégano, palto y } \\
\text { damasco. }\end{array}$ \\
\hline
\end{tabular}

Fuente: Elaboración propia, 2006

obtiene de promediar los valores de las utilidades anuales de las áreas de influencia de la Cía. Minera mostrados en el cuadro 2, producto del trabajo de campo. Asimismo, dicha cifra representa la mayor utilidad económica entre las cadenas productivas identificadas.

$$
\begin{aligned}
& \text { DIAGNÓSTICO DE LA LADENA PRODUCTIVA } \\
& \text { DEL ORÉGANO }
\end{aligned}
$$

Debido a la gran similitud que presentan las cadenas productivas del orégano, en cada zona, se decidió agruparlas y estudiarlas como una sola cadena.

Mapeo de la cadena productiva del orégano seco

La cadena productiva del orégano está conformada por los siguientes eslabones:

- Primer eslabón.- Constituido por pequeños y medianos productores agrícolas individuales o asociaciones. Estos productores poseen en promedio un terreno de 0,5 hectáreas, quienes obtie- nen un rendimiento promedio de $3547 \mathrm{Kg}$. de orégano seco por hectárea en un año.

- Segundo eslabón.- Constituido por los acopiadores e intermediarios locales, quienes compran el orégano a granel en la chacra, en sacos de $46 \mathrm{Kg}$ y lo revenden al transformador 0 comercializador mayorista.

- Tercer eslabón.- Constituido por empresas transformadoras que le agregan valor al orégano a granel (orégano seco y despalillado), el orégano es clasificado en diferentes calidades por calibre (en mm.) en máquinas de zaranda, molidas en algunos casos para homogeneizar el producto, luego son embolsadas, empaquetadas y comercializadas, generalmente al mercado exterior.

- Cuarto eslabón.- Conformado por los consumidores finales nacionales y extranjeros como: Chile, Brasil, Argentina, Alemania, España y Colombia.

En la figura 2 se identifican a los actores directos de cada eslabón de la cadena productiva del orégano.

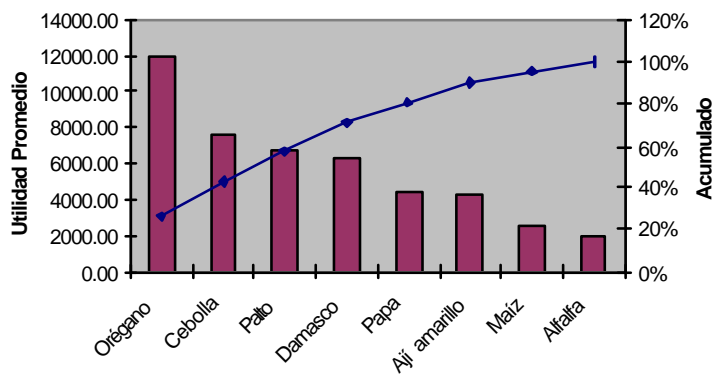

Figura 1. Pareto de la utilidad por cultivo 


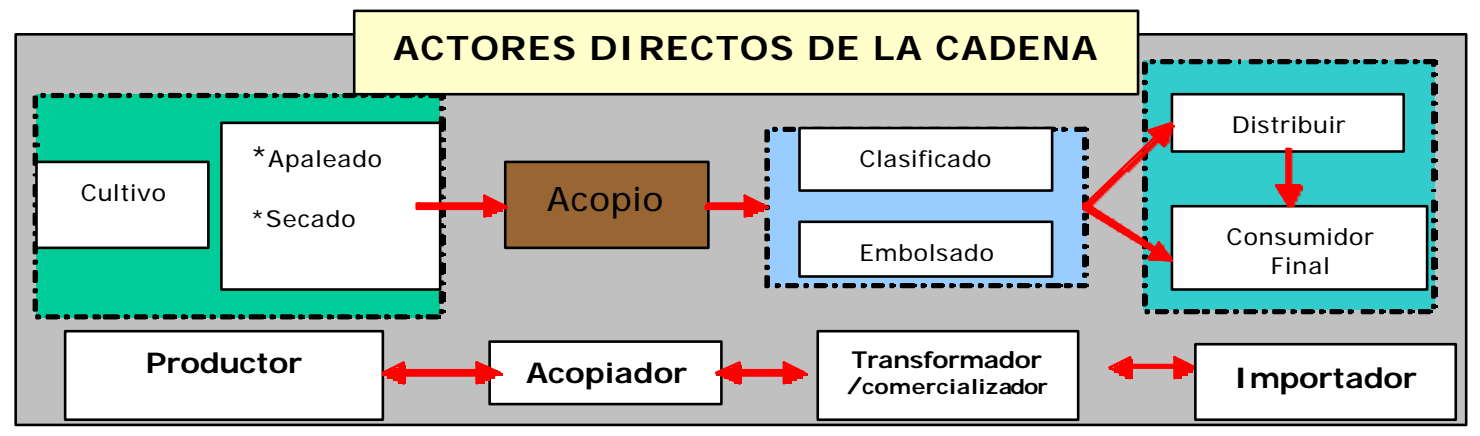

Figura 2. Actores directos a la cadena productiva del orégano

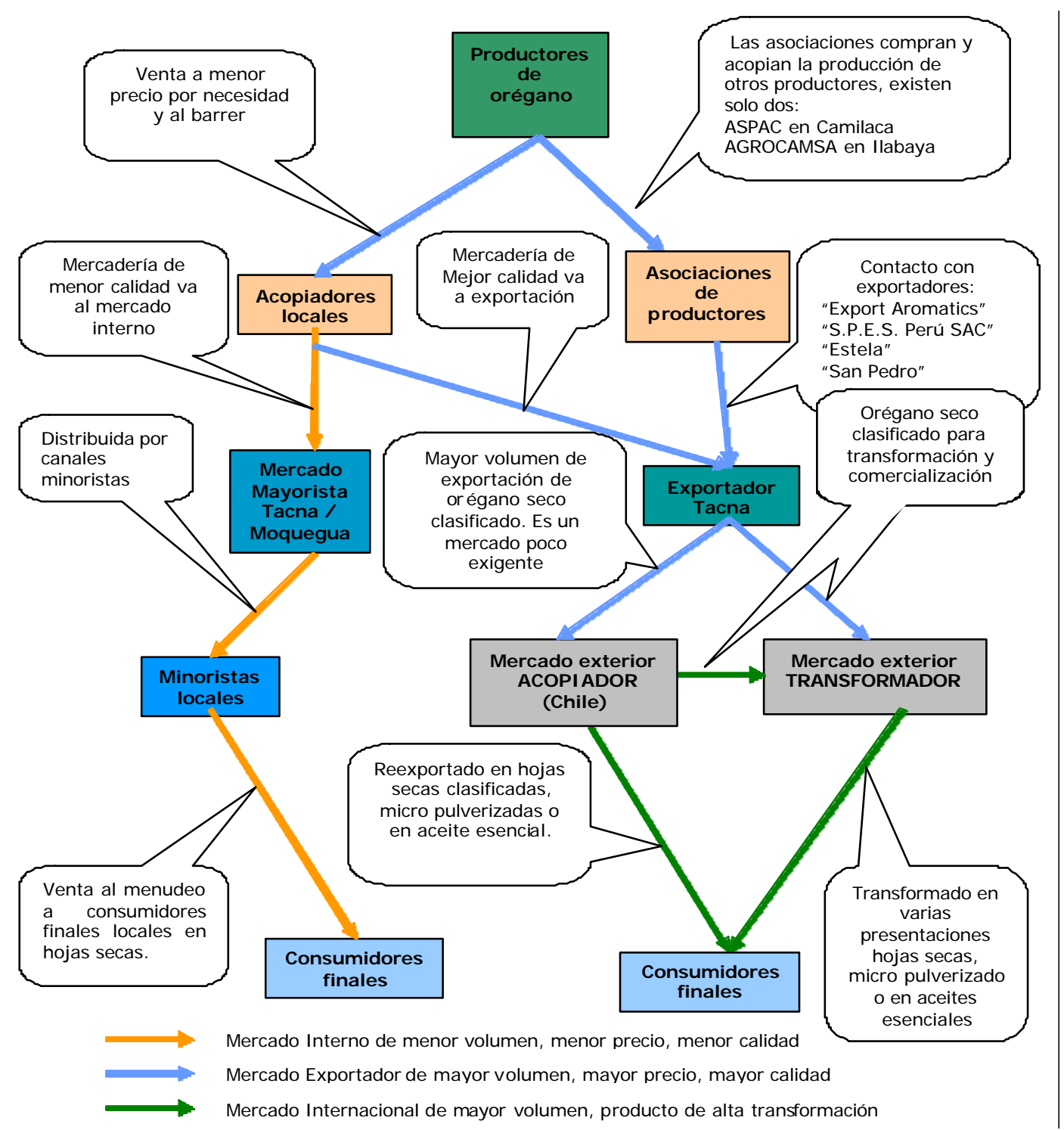

Figura 3. Flujo de relación entre actores de la cadena productiva del orégano 
Cuadro 3. Matriz de caracterización de la cadena productiva del orégano

\begin{tabular}{|c|c|c|c|c|}
\hline \multirow[b]{2}{*}{ Identificación } & \multicolumn{4}{|c|}{ Agentes Directos } \\
\hline & Producción & Acopiadores & $\begin{array}{l}\text { Transformación } \\
\text { /Comercialización }\end{array}$ & Clientes / transformadores. \\
\hline Actores & 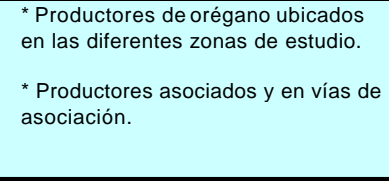 & $\begin{array}{l}\text { * Intermediarios de la } \\
\text { zona. } \\
{ }^{*} \text { Acopiadores de } \\
\text { empresas } \\
\text { exportadoras. }\end{array}$ & $\begin{array}{l}\text { * Mercado mayorista de } \\
\text { Tacna. } \\
\text { * Empresas } \\
\text { exportadoras. }\end{array}$ & $\begin{array}{l}{ }^{*} \text { Países extranjeros } \\
\text { acopiadores Chile. } \\
\text { *Paises extranjeros } \\
\text { transformadores } \\
\text { consumidores Brasil, } \\
\text { Argentina, Alemania, etc. }\end{array}$ \\
\hline Actividad & $\begin{array}{l}\text { * Cultivo y cosecha de orégano. } \\
\text { * Venta a granel de orégano seco. }\end{array}$ & $\begin{array}{l}\text { * Compra en chacra } \\
\text { y venta al } \\
\text { exportador. }\end{array}$ & $\begin{array}{l}\text { * Clasifica, embolsa y } \\
\text { empaqueta. } \\
\text { * Mercados, } 60 \% \\
\text { exportación y } 40 \% \\
\text { mercado interno. } \\
\end{array}$ & $\begin{array}{l}\text { *Acopio y Reprocesamiento. } \\
\text { *Utilización en industria } \\
\text { cárnica. }\end{array}$ \\
\hline Estrategias & $\begin{array}{l}\text { * Siembra. } \\
\text { * Cultivo. } \\
\text { * Cosecha. } \\
\text { * Post cosecha. } \\
\text { * El Orégano es vendido a granel en } \\
\text { sacos de } 46 \mathrm{~kg} .\end{array}$ & $\begin{array}{l}{ }^{*} \text { Establecer precios } \\
\text { por campaña. } \\
\\
{ }^{*} \text { Abastecer } \\
\text { exportadores y } \\
\text { mayoristas. }\end{array}$ & $\begin{array}{l}\text { * Clasifican y embalan } \\
\text { según requerimiento del } \\
\text { cliente. }\end{array}$ & $\begin{array}{l}{ }^{*} \text { Comprar el producto con } \\
\text { bajo valor agregado y } \\
\text { agregarle valor. } \\
\text { * Reexportación como } \\
\text { producto propio. }\end{array}$ \\
\hline Riesgos & $\begin{array}{l}\text { * Manipulación del precio por parte del } \\
\text { intermediario. } \\
\text { * Bajo capital de trabajo. } \\
\text { * Falta de recurso hídrico. } \\
\text { * Fenómenos naturales desfavorables. }\end{array}$ & $\begin{array}{l}{ }^{*} \text { Productores } \\
\text { asociados con mayor } \\
\text { poder de } \\
\text { negociación. }\end{array}$ & $\begin{array}{l}\text { * Baja calidad del } \\
\text { producto comercializado. } \\
\text { * Creciente número de } \\
\text { empresas } \\
\text { comercializadoras. } \\
\text { * Normas de calidad más } \\
\text { exigentes. }\end{array}$ & * La calidad del producto. \\
\hline Resultados & ${ }^{*}$ Agricultura de subsistencia. & $\begin{array}{l}{ }^{*} \text { Nivel medio de } \\
\text { ingresos con poco } \\
\text { esfuerzo. }\end{array}$ & 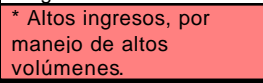 & $\begin{array}{l}\text { * Reconocimiento del orégano } \\
\text { como producto propio. }\end{array}$ \\
\hline
\end{tabular}

Fuente: Elaboración propia, 2006

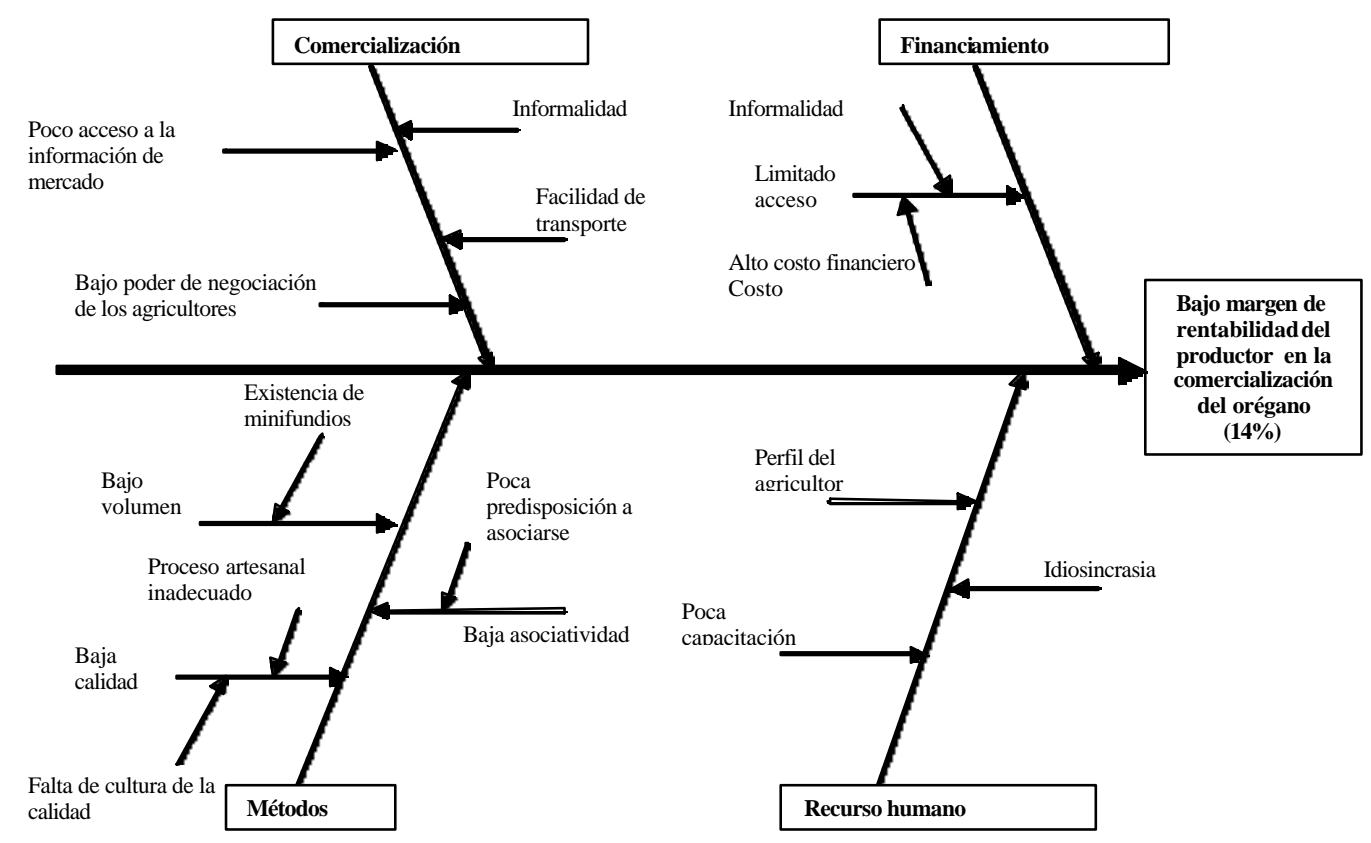

Figura 4. Diagrama Causa-Efecto: Bajo Margen de la rentabilidad en la comercialización de orégano 
Cuadro 4. Precios del orégano

\begin{tabular}{lc}
\hline & Valor \\
Precio del agricultor al acopiador & $\mathrm{S} / .5,80$ \\
\hline Precio del acopiador al exportador & $\mathrm{S} / .6,80$ \\
\hline Margen de comercialización & $\mathrm{S} / .15,86$
\end{tabular}

Fuente: Elaboración propia, 2006

ANÁlisis DE LA CADENA PRODUCTIVA
DEL ORÉGANO
Análisis causa - efecto de la cadena
productiva del orégano
Se analizaron los efectos más visibles en el eslabón primario:

1. Pérdida del productor en el margen de comercialización de orégano.

2. Bajo precio del orégano por deficiente secado.

En el diagrama Ishikawa, mostrado en la Figura 5 se muestran las causas de la pérdida en el margen de comercialización del productor. Estas causas se confrontaron a través de una matriz de enfrentamiento y
Cuadro 5. Priorización de causas

\begin{tabular}{|cl|}
\hline $\mathbf{N}$ o & \multicolumn{1}{c|}{ Causas } \\
$\mathbf{1}$ & Baja Asociatividad \\
\hline $\mathbf{2}$ & Baja Calidad \\
$\mathbf{3}$ & Bajo Volumen
\end{tabular}

Fuente: Elaboración propia, 2006

fueron priorizadas utilizando la técnica de Pareto, el resultado se muestra en el Cuadro 5.

En el diagrama Ishikawa de la Figura 5 se muestran las causas de la merma en la calidad durante el proceso de secado del orégano. Estas causas se confrontaron a través de una matriz de enfrentamiento y fueron priorizadas utilizando la técnica de Pareto, el resultado se muestra en el Cuadro 6.

Se observa que, implementando las estrategias para fomentar y fortalecer la asociatividad y el tecnificado del proceso de secado, se puede incidir directamente en la solución de los dos problemas más importantes de la cadena productiva del orégano en la zona deestudio.

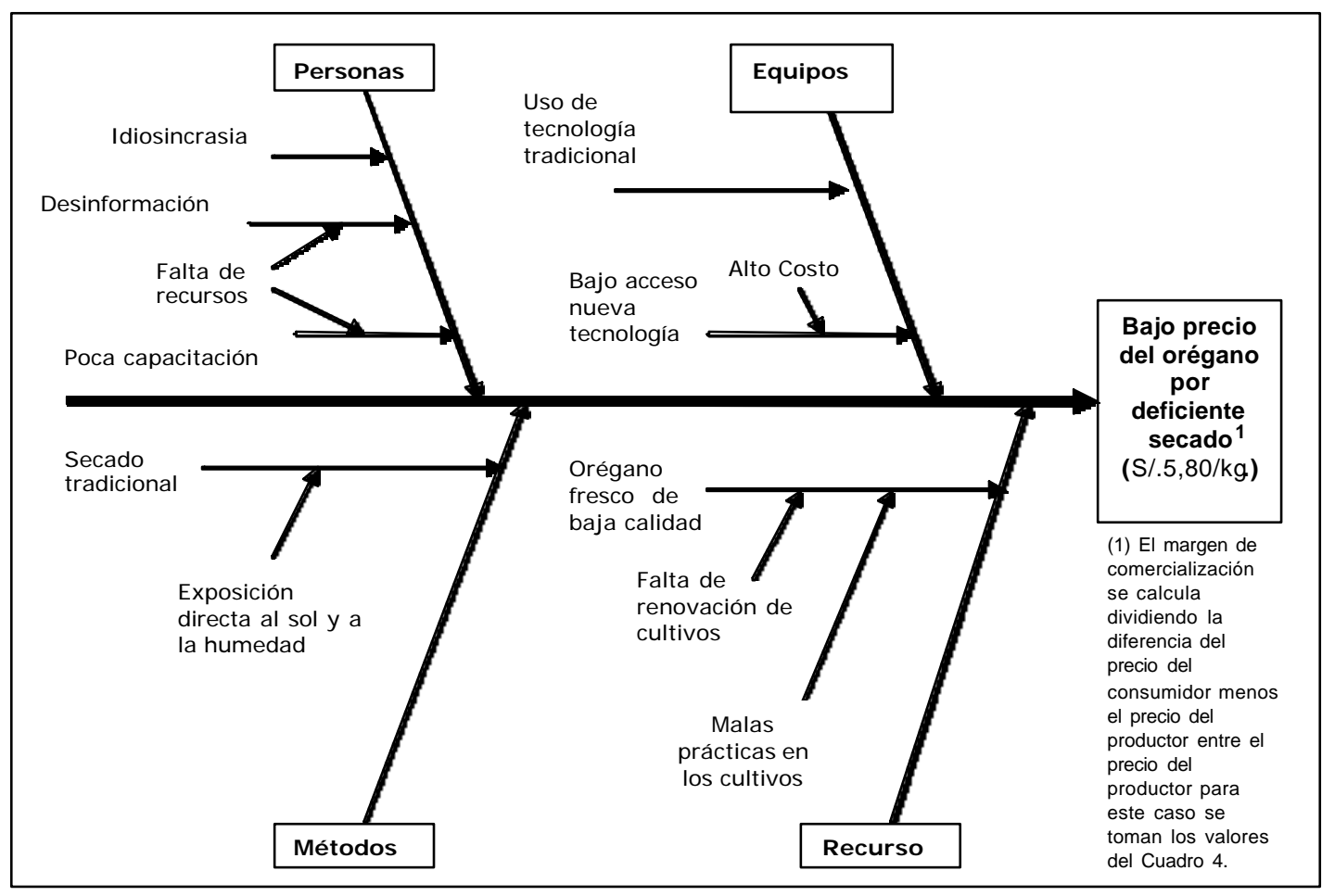

Figura 5. Diagrama Causa-Efecto: Bajo precio del orégano por deficiente secado 
Cuadro 6. Priorización de causas

\begin{tabular}{|c|c|}
\hline № & \multicolumn{1}{|c|}{ Causas } \\
\hline $\mathbf{1}$ & Uso de tecnología tradicional \\
\hline $\mathbf{2}$ & Secado tradicional inadecuado \\
\hline $\mathbf{3}$ & Alto costo de nueva tecnología \\
\hline
\end{tabular}

Fuente: Elaboración propia, 2006

C O N C L U S I O N E S

La primera causa que impide el desarrollo de la cadena productiva del orégano es la baja asociatividad de los productores que, -unido a la micro parcelación- originan un bajo volumen ofertable y una producción no estandarizada, disminuyendo la capacidad de negociación del productor frente al acopiador, esto se refleja en la baja rentabilidad de la comercialización del orégano.

La pérdida de calidad del producto se da en los procesos de cosecha, durante el cote de matas del orégano (corte del cultivo), éstas se orean sobre la tierra, contaminándose. Durante la post cosecha (secado y apaleado); se realiza el proceso de secado tradicional exponiendo al sol los cotes de orégano extendidos en algunos casos sobre mantas y en muchos otros sobre la tierra. La exposición directa al sol reduce el contenido de aceites esenciales del orégano e incluso le cam- bia el aspecto a las hojas, pasando de un color verde a un verde pálido sin vida.

Los productores no cumplen con las normas internacionales (ficha técnica) que exigen estándares en las características organolépticas, químicas y los requisitosmicrobiológicos.

Existe limitado acceso al mercado por la existencia de acopiadores, falta de información de clientes potenciales y el mercado en general.

RE COM E N D A C I O N E S

En el corto plazo

Fortalecer la cadena productiva del orégano a nivel del eslabón primario, mediante la asociatividad de los productores a fin de manejar grandes volúmenes, lograr productos homogéneos y conseguir capacidad de negociación para obtener mejores precios en el mercado. Además, se debe concientizar a los productores en ampliar la frontera agrícola del orégano, por ser éste el de mayor rentabilidad.

Dictar talleres de mejoramiento de la calidad del producto e implementarlas; desde selección de semillas, uso de abonos orgánicos, control biológico de plagas, manipulación tecnificada del producto para cumplir las exigencias del mercado internacional.

Cuadro 7. Matriz FODA

\begin{tabular}{|c|c|c|}
\hline $\begin{array}{l}\text { FACTORES } \\
\text { EXTERNOS }\end{array}$ & $\begin{array}{l}\text { Fortalezas: } \\
\text { 1.- Cultivo altamente rentable. } \\
\text { 2.- Calidad del "Orégano Peruano" reconocida en el } \\
\text { mercado mundial. } \\
\text { 3.- Condiciones naturales favorables para el cultivo. } \\
\text { 4. Apoyo técnico de empresas públicas y privadas. } \\
\text { 5.- Estabilidad macroeconómica. }\end{array}$ & $\begin{array}{l}\text { Debilidades: } \\
\text { 1.- Bajo valor agregado en la producción. } \\
\text { 2.- Existencia de minifundismo. } \\
\text { 3.- Bajo nivel de asociatividad de agricultores. } \\
\text { 4.- Proceso inadecuado de secado, que provoca } \\
\text { baja calidad. } \\
\text { 5.- Insuficiencia y mal uso del recurso hídrico. }\end{array}$ \\
\hline $\begin{array}{l}\text { Oportunidades: } \\
\text { 1.- Tendencia creciente de la demanda } \\
\text { internacional. } \\
\text { 2.- Disponibilidad de terrenos cultivables. } \\
\text { 3.- Existencia de mercados para nuevas } \\
\text { presentación del producto. } \\
\text { 4.- Acuerdos de preferencia arancelaria. } \\
\text { 5.- Mayor precio y demanda creciente de productos } \\
\text { orgánicos en Europa. }\end{array}$ & $\begin{array}{l}\text { Estrategias FO: } \\
\text { - } \quad \text { mpliar la superficie cultivable de orégano en la } \\
\text { región, aprovechando la disponibilidad de } \\
\text { terrenos apropiados para su producción. } \\
\text { - Generar oferta exportable en productos de } \\
\text { mayor valor agregado. } \\
\text { - Ingreso a nuevos mercados de mayores } \\
\text { precios por productos de mayor valor agregado. }\end{array}$ & $\begin{array}{l}\text { Estrategias DO: } \\
\text { - } \quad \text { Fortalecer la asociatividad para ofrecer mayor } \\
\text { volumen exportable. } \\
\text { - Crear valor agregado en la cadena, para } \\
\text { ingresar a los mercados externos. } \\
\text { - } \quad \text { Fortalecer las organizaciones de produ ctores } \\
\text { - Introducción de equipos tecnológicos que } \\
\quad \text { permitan mejorar la calidad y la producción. }\end{array}$ \\
\hline $\begin{array}{l}\text { Amenazas: } \\
\text { 1.- Fenómenos climáticos. } \\
\text { 2.- Monopolio de acopiadores locales. } \\
\text { 3.- Fluctuaciones de precios internacionales. } \\
\text { 4.- Disminución de mano de obra por migración } \\
\text { hacia zonas urbanas. } \\
\text { 5.- Exigencias de calidad más rigurosas en los } \\
\text { mercados demandantes. }\end{array}$ & $\begin{array}{l}\text { Estrategias FA: } \\
\text { - Crear programas de contingencia para prevenir } \\
\text { - } \quad \text { Crómenos naturales adversos. } \\
\text { - } \quad \text { Fomentar la indus de calidad en el productor. } \\
\quad \text { generar empleo. }\end{array}$ & $\begin{array}{l}\text { Estrategias DA: } \\
\text { - Fomentar la asociatividad entre productores. } \\
\text { - Eliminar intermediarios entre los productores y } \\
\text { exportadores. } \\
\text { - Tecnificación del manejo en el recurso hídrico. } \\
\text { - Tecnificar el proceso de secado, para mejorar la } \\
\text { calidad de lotes exportados. } \\
\text { - Generar trabajo en las zonas productoras, dando } \\
\text { valor agregado al producto. }\end{array}$ \\
\hline
\end{tabular}

Fuente: Elaboración propia, 2006 
PROYECTO

DISEÑO DEL PROTOTIPO DE LA CÁMARA DE SECADO SOLAR - EÓlICO

La principal ventaja de la cámara de secado solar - eólico radica en la limpieza y homogeneidad del producto final, conservando el orégano sus características organolépticas, y la posibilidad de contar con una superficie de secado a bajo costo. El diseño del secador propuesto es modular, es decir se crece en capacidad según la necesidad del productor, el modelo expuesto posee una capacidad de 167 $\mathrm{Kg}$. de orégano fresco, las características técnicas del prototipo y las condiciones del sistema se muestran a continuación:

Características Técnicas

\begin{tabular}{|l|l|l|}
\hline 1 & Capacidad del secador & $167 \mathrm{Kg}$. orégano fresco \\
\hline 2 & Tiempo esperado de secado & 30 horas \\
\hline 3 & Rendimiento del secador & $4,2 \mathrm{~kg} . /$ hora \\
\hline 4 & Dimensiones & $1,5 \times 2,0 \times 2,57 \mathrm{mts}$ \\
\hline 5 & Distribución por bandeja & $8 \mathrm{~kg} \times \mathrm{m}^{2}$ de orégano fresco \\
\hline
\end{tabular}

Condiciones del Sistema

\begin{tabular}{|c|l|c|}
\hline 1 & Velocidad mínima esperada del aire dentro del módulo & $25 \mathrm{~cm} / \mathrm{seg}$ \\
\hline 2 & Temperatura de secado & Menor a $40^{\circ} \mathrm{C}$ \\
\hline 3 & Humedad relativa del sistema & $30^{\circ}$ \\
\hline
\end{tabular}

Plano del prototipo

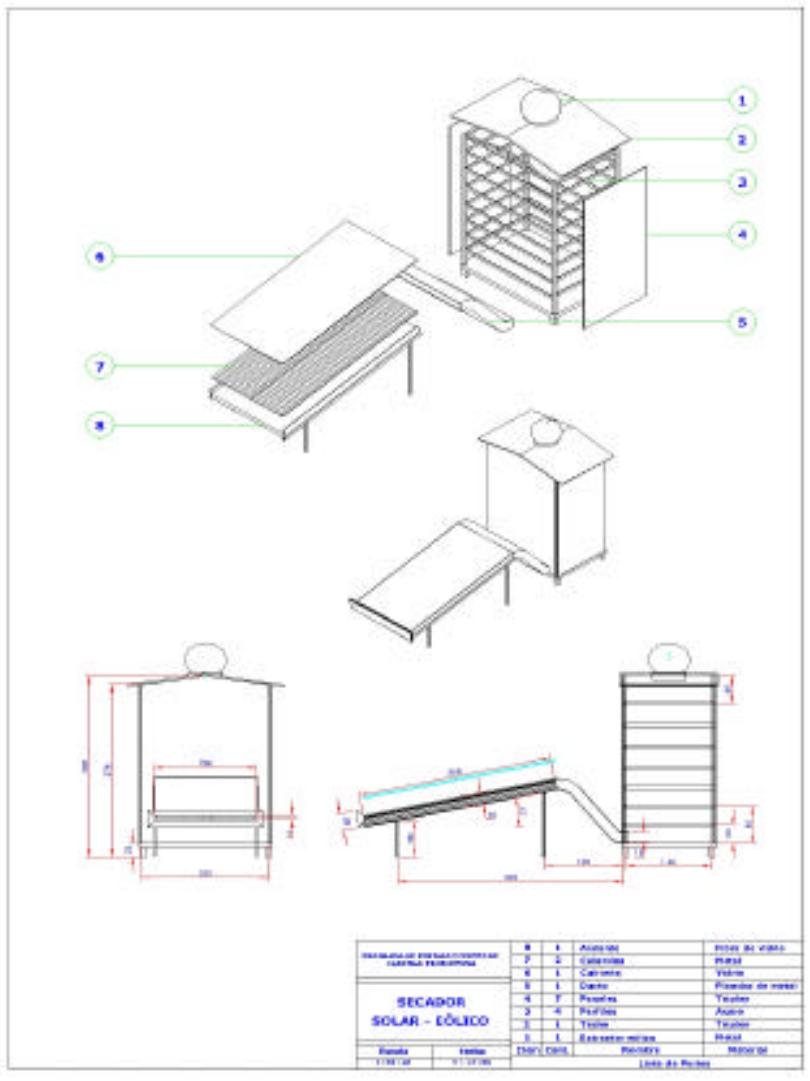

Figura 6. Especificaciones técnicas del prototipo de la cámara de secado solar - eólico. 
Cuadro 8. Costo estimado de implementación del prototipo de Cámara de Secado Solar - Eólico

\begin{tabular}{|c|l|l|c|r|r|}
\hline Nro. & Descripción & Material & Cantidad & $\begin{array}{c}\text { Precio } \\
\text { Unit(S/.) }\end{array}$ & $\begin{array}{c}\text { Precio } \\
\text { Total(S/.) }\end{array}$ \\
\hline 1 & Aislante & Estructura de Fibra de vidrio & 1 unid & 650 & 650 \\
\hline 2 & Calamina & Metal & 2 unid. & 28 & 56 \\
\hline 3 & Cubierta & Vidrio & $2,56 \mathrm{~m}^{2}$ & 100 & 100 \\
\hline 4 & Ducto / Túnel & Latón & 1 Plancha & 28 & 28 \\
\hline 5 & Paneles / Techo & Triplay & 7 Planchas & 70 & 490 \\
\hline 6 & Malla & Nylon & $21 \mathrm{~m}^{2}$ & 4 & 84 \\
\hline 7 & Perfiles & Acero & 4 und. & 34 & 136 \\
\hline 8 & Marcos & Madera & $6 \mathrm{Kg}$ & 6 & 102 \\
\hline 9 & Desecante & Silica Gel Bulk & 1 und. & 80 & 480 \\
\hline 10 & Extractor Eólico & Metal & varios & 10 & 300 \\
\hline 11 & Ferretería & Tuercas, tornillos, alambres & & 300 & 300 \\
\hline 12 & Mano de obra & Servicio fabricación & & TOTAL S/. & $\mathbf{2 7 3 6}$ \\
\hline & & & &
\end{tabular}

Fuente: Elaboración propia, 2006

Mejorar las técnicas de secado con tecnologías adaptables a dichas zonas. Para este fin se diseñó una cámara de secado solar eólico, la cual reducirá el tiempo de secado (tiempo de ciclo) del orégano de 8 días a 1 día y elevará la calidad del producto con el consiguiente beneficio de S/. 0,90/kg. para el agricultor (precio con mejora S/.6,70 - precio actual: S/ $.5,80 / \mathrm{kg}$.). Este sólo aporte tendría un gran impacto económico en la zona, si se considera que anualmente se cosechan 3283 toneladas de orégano, lo que multiplicado por el diferencial dejado de percibir S/. 2'954 700 (328 300 kg. x S/. 0,90).

Los planos, especificaciones y costos de la cámara de secado solar eólica diseñada se encuentran explicados en la Figura 6 y Cuadro 8.

En el largo plazo

Introducir en la zona nuevos cultivos de plantas aromáticas de mayor rentabilidad que los cultivos actualmente sembrados, tales como: menta, tomillo, romero, mejorana.

Fomentar la formación de empresas transformadoras y exportadoras en la zona, teniendo como accionistas a los productores locales asociados o consorciados.

\section{A GR A D E I M I E N T O}

Es importante agradecer el valioso y decidido apoyo de los Sres. Joel Huamán Basaldúa, Alan Grau Correa, Jorge Gallardo Vela, Brack Hernández Carranza, José Valle Salinas, Maik Espinoza Cenzano, Miguel
Camacho Izquierdo y Moisés Santos Andrade, egresados y estudiantes de la Facultad de Ingeniería Industrial de la Universidad Nacional Mayor de San Marcos, quienes han sido participantes de esta experiencia generando un espacio para el fortalecimiento de la vinculación Universidad-Empresa. Asimismo al Dr. Manuel Sierra López, quien se encargó personalmente de brindar el apoyo logístico y administrativo al equipo de trabajo.

REFERENCIAS

BIBLIOGRÁF ICAS

1. Censo Nacional $X$ de Población y $V$ de Vivienda 2005. Instituto Nacional de Estadística e Informática, INEI. En: www.inei.gob.pe (17/11/06).

2. Compendio Estadístico Regional de Tacna 20042005. Gobierno Regional de Tacna. En: www.agritacna.gob.pe (05/10/06).

3. Diagnóstico Agrario 2004. Dirección Regional Agraria Tacna. En: www.agritacna.gob.pe (15/12/06).

4. Gobierno Regional Tacna. (2006). En: www.tacnaexporta.gob.pe (25/10/06).

5. Ministerio de Agricultura (2006). estadísticas Agrarias. En: www.minag.gob.pe/estadistica.shtml (30/10/06).

6. Vásquez H., Enrique; Aramburu L., y Otros (2000). Gerencia Social. Diseño, Monitoreo y Evaluación de Proyectos Sociales. Universidad del Pacífico. Lima, Perú. 